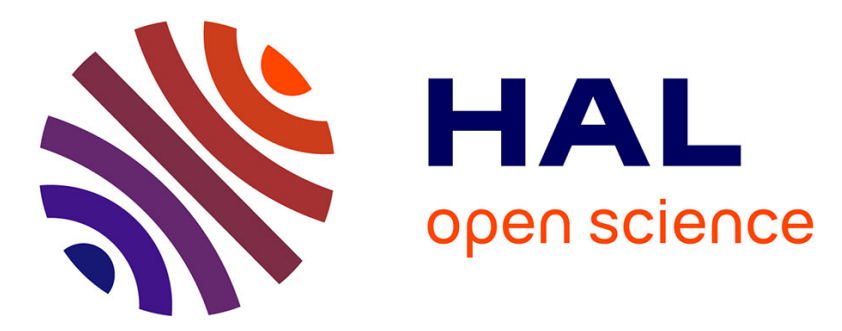

\title{
Impact of the Economic Environment Modelling for the Optimal Design of a Multi-Energy Microgrid
}

\author{
Remy Rigo-Mariani, Sean Ooi Chea Wae, Stefano Mazzoni
}

\section{To cite this version:}

Remy Rigo-Mariani, Sean Ooi Chea Wae, Stefano Mazzoni. Impact of the Economic Environment Modelling for the Optimal Design of a Multi-Energy Microgrid. IECON 2020 - 46th Annual Conference of the IEEE Industrial Electronics Society, Oct 2020, Singapore, Singapore. pp.1837-1842, 10.1109/IECON43393.2020.9254730 . hal-03016150

\section{HAL Id: hal-03016150 \\ https://hal.science/hal-03016150}

Submitted on 20 Nov 2020

HAL is a multi-disciplinary open access archive for the deposit and dissemination of scientific research documents, whether they are published or not. The documents may come from teaching and research institutions in France or abroad, or from public or private research centers.
L'archive ouverte pluridisciplinaire HAL, est destinée au dépôt et à la diffusion de documents scientifiques de niveau recherche, publiés ou non, émanant des établissements d'enseignement et de recherche français ou étrangers, des laboratoires publics ou privés. 


\section{Impact of the Economic Environment Modelling for the Optimal Design of a Multi-Energy Microgrid}

\author{
Rémy Rigo-Mariani \\ Univ. Grenoble Alpes, CNRS, Grenoble \\ INP*, G2Elab, 38000 Grenoble, France \\ remy.rigo-mariani@g2elab.inp- \\ grenoble.fr
}

\author{
Sean Ooi Chea Wae \\ Energy Research Institute @ NTU \\ Nanyang Technological University \\ Singapore, Singapore \\ seanooi@ntu.edu.sg
}

\author{
Stefano Mazzoni \\ Energy Research Institute @ NTU \\ Nanyang Technological University \\ Singapore, Singapore \\ mstefano@ntu.edu.sg
}

\begin{abstract}
The paper discusses the impact of the problem formulation for the optimal design of a multi-energy microgrid. The study shows that the energy rates affect the output results much more than any other parameter such as the cost of equipment or the assets efficiencies (ratio 1 to 100). The main focus of the paper is then the representation of the economic environment for such a planning problems. Five different modeling approaches are investigated with both deterministic and stochastic methods (scenario-based formulation), as well as constant or increasing rates along the planning horizon. The obtained results show great impacts on the installed capacities (variations from simple to triple for the gas engine rated power), while the objective function (i.e. system cost of ownership) displays small variations less than $5 \%$ with the different sets of hypothesis. The papers then concludes on a recommendation to present the results in terms of optimal areas instead of a single global optimum for such problems.
\end{abstract}

Keywords-Multi-Energy, Optimal Planning, Stochastic Optimization, Linear Programming Introduction

\section{NOMENCLATURE}

Operating Variables :

\begin{tabular}{|c|c|}
\hline$P_{t}^{g e}, M_{t}^{g e}$ & gas engine power/fuel at time $t(\mathrm{~kW}, \mathrm{~kg} / \mathrm{h})$ \\
\hline$P_{t}^{p v}$ & solar generation at time $t(\mathrm{~kW})$ \\
\hline$P_{t}^{\text {bat }{ }^{+}}, P_{t}^{\text {bat }-}$ & battery charge/discharge at time $t(\mathrm{~kW})$ \\
\hline$P_{t}^{g d}$ & grid power at time $t(\mathrm{~kW})$ - generator conv. \\
\hline$P^{g d P}$ & grid peak power along the emulated period $(\mathrm{kW})$ \\
\hline$P_{t}^{c h}$ & chiller plant electrical load at time $t(\mathrm{~kW})$ \\
\hline$P_{t}^{a b c h}$ & absorption chiller electrical load at time $t(\mathrm{~kW})$ \\
\hline$Q_{t}^{c h}$ & chiller plant cooling power at time $t(\mathrm{RT})$ \\
\hline$Q_{t}^{a b c h}$ & absorption chiller cooling power at time $t(\mathrm{RT})$ \\
\hline$Q_{t}^{t s+}, Q_{t}^{t s-}$ & charging/discharging power of $t s$ at time $t(\mathrm{RT})$ \\
\hline$S O C_{t}^{b a t}, S O C_{t}^{t s}$ & battery/th. storage state of charge at time $t(\%)$ \\
\hline
\end{tabular}

Sizing Variables:

$P^{g e R}, P^{p v R} \quad$ gas engine/solar gen. rated powers $(\mathrm{kW}, \mathrm{kWp})$

$E^{\text {batR }}, E^{t s R} \quad$ battery/th. storage capacities (kWh - RTh)

$Q^{t s R} \quad$ thermal storage rated power (RT)

Parameters:

$P_{t}^{l}, Q_{t}^{l} \quad$ electrical/thermal load at time $t(\mathrm{~kW}, \mathrm{RT})$

$P_{t}^{p v N} \quad$ normalized solar generation at time $t(-)$

$\pi_{t}^{e}, \pi^{p}, \pi_{t}^{e} \quad$ elect./peak/gas prices $(\$ / \mathrm{kWh}, \$ / \mathrm{kW}, \$ / \mathrm{kg})$ $\alpha^{g e}, \beta^{g e} \quad$ coefficients for gas engine operating cost

$\eta^{\text {bat }}, \eta^{\text {ts }} \quad$ battery and thermal storage efficiencies (-)

$\underline{S O C^{b a t}}, \overline{S O C^{b a t}}$ battery min/max state of charge (\%)

$\underline{S O C^{t s}}, \overline{S O C^{t s}} \quad \mathrm{~min} / \mathrm{max}$ state of charge of battery $t s(\%)$

$S O C_{0}^{b a t}, S O C_{0}^{t s} \quad$ battery and thermal storage initial SOC (\%)

$\mathrm{COP}^{\mathrm{ch}} \quad$ chiller plant coefficient of performance (-)

COPabch absorption chiller coefficient of performance (-)

$\beta_{p w h}^{a b c h} \quad$ absorption chiller power/heat ratio $(\mathrm{RT} / \mathrm{kW})$

$\beta_{p c r}^{a b c h} \quad$ absorption chiller cooling ratio ( $\left.\mathrm{kW} / \mathrm{RT}\right)$

\section{INTRODUCTION}

Multi energy systems have long been proved to enhance the integration of renewable energy sources by providing efficiency and flexibility with the interaction of different energy vectors [1]. The optimal design of so-called "multienergy microgrids" has been extensively addressed in the literature. Such problems consist in finding the best capacities of the assets (solar generator, co-generation plant, electrical/thermal storages, etc) with a tradeoff between the capital expenditures and the operating cost estimated along the system lifetime [2]. Such decision processes are subject to a wide range of uncertainties that has to be taken into consideration in the design phase - uncertainties regarding the load level, the renewable generation, the energy prices, the investment costs as well as the models accuracy [3]. Considering those uncertainties may lead to prohibitive computational times is usually tackled with different approaches mixed with simplified linear models of the systems. Typical methods rely on robust optimization with the definition of best/worst case scenarios that represent the volatility of uncertain parameters [4]. Other methods introduce chance constraints while setting a tolerance on the probability to meet specific operating conditions (typically power balance) [5]. Finally, scenario-based stochastic optimization is the most widely used approach. It define sets of potential scenario (with uniform or normal distribution to represent the uncertainties). The objective function is then formulated as the sum of the optimal results for each scenario weighted by the corresponding probability of occurrence [6] [7]. It is important to note that the majority of those studies consider the uncertainties for the load profiles and renewablebased generation. This paper investigates the relevance of the uncertainties consideration on a generic benchmark and with 
a design problem that is solved using simple linear programming. Is the system design significantly impacted in terms of installed capacities or objective function (typically cost)? Do those impacts justify the degree of complexity and associated computational time of advanced stochastic optimization techniques? After the problem is presented in Section III, a sensitivity analysis identifies the energy costs (i.e. electricity and gas here) as the most influent parameters. Section IV then investigates different representations of the economic environment before the planning problem is run for different hypothesis and the conclusions are drawn in Section V.

\section{CASe Study AND Modeling}

\section{A. Considered System}

The work presented in this paper has been led in the framework of the Smart Multi Energy System (SMES) project, whose objective is the implementation of an energy management strategy at a building scale or for a cluster of buildings for the co-operation of electrical and cooling systems. Indeed, this approach facilitates two key transitions necessary for achieving reduced carbon emissions in the long term: 1) it enhances the integration of renewable energy sources and 2) it increases the overall system efficiency by exploiting the interaction between different energy vectors. Figure 1 displays the single line diagram of the considered system and highlights the interface of both thermal and electrical networks at the chiller plant level and with the combination gas engine / absorption chiller. Both thermal and electrical load profiles corresponds to an office/research building located in Singapore with more than two years recorded data in addition to solar radiation measurements [8]. For the sake of simplicity and in the absence of seasonality effects on the loads and solar generation, the system operation is simulated along a single representative week. It should be noted that the representation of the simulation period (i.e. system lifetime) is an area of research by itself with the appropriate techniques ([9]) (e.g. downsampling, clustering) which are not in the scope of the proposed work.

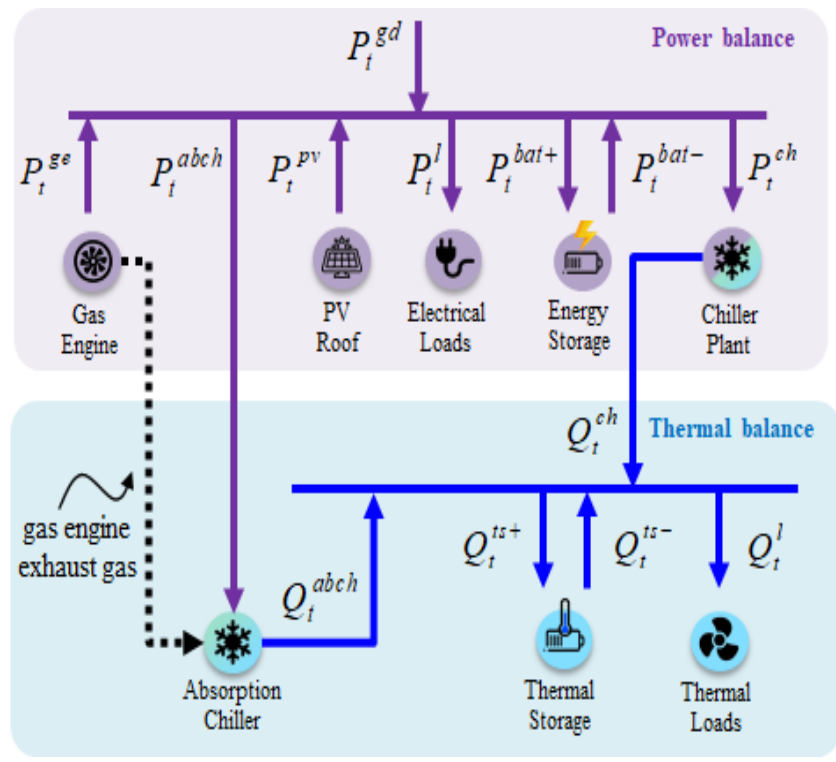

Figure 1. Considered Multi Energy System
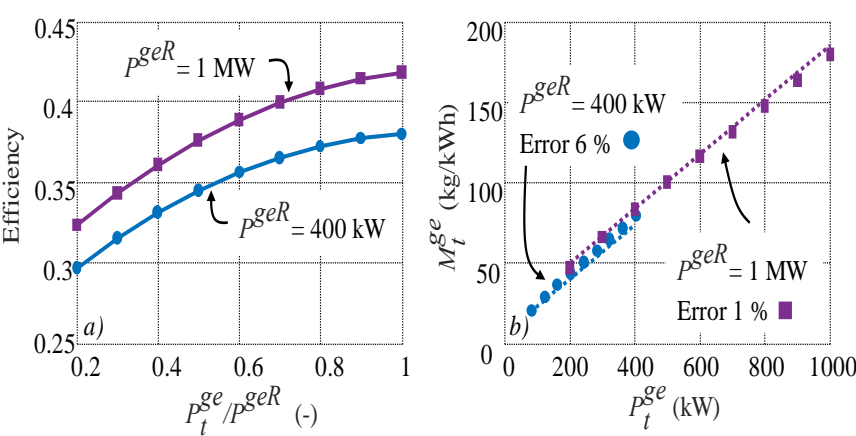

Figure 2. Gas engine model - a) Efficiency vs Operating Point - b) Fitting of the consumption curves

\section{B. Linear Modeling for Planning Study}

\section{1) Gas Engine Model:}

Specific attention is paid to the model of the gas engine depending on the operating point and the rated power. As different engine sizes and operating conditions will be investigated in the course of the optimal planning, there is a need for simple/fast models in order to avoid prohibitive computational times. At first, a quadratic formulation is considered and highlights the strong impact of the operating point and rated capacity on the engine efficiency (Figure 2a) [10]. With the considered model, the gas engine consumption $M_{t}^{g e}$ (in $\mathrm{kg} / \mathrm{kWh}$ ) can then be computed with the fuel lower heating value $\left(\mathrm{LHV}=48,000 \mathrm{~kJ} / \mathrm{kg}\right.$ ) for different sizes $P^{g e R}$ and output power $P_{t}^{g e}$. This model is then furtherly used to implement a linear formulation of the fuel consumption with the operating point and rated capacity of the engine. At first, a least square minimization is applied in order to fit a set of consumption curves for different classes of engines (Figure $2 b$ ) with an overall error of $3.5 \%$. Finally, that curve fitting allows to express the consumption linearly with the engine power and size by utilizing the coefficient denoted $\alpha^{g e}$ and $\beta^{g e}((1))$.

$M_{t}^{g e}=\alpha^{g e} \times P^{g e R}+\beta^{g e} \times P_{t}^{g e}$

\section{2) 'All in One' Problem Formulation - OPTo}

As previously mentioned, the scope of the work presented here is to investigate the impact of the input parameters and problem formulation on the obtained results. The optimal planning of the system is formulated using linear programming in order to avoid long computational times and allow to test several formulations. Typical approaches encountered in the literature tackle the planning problem with bi-level architectures. An inner loop optimizes the system operation while an outer loop investigates different configurations by using evolutionary methods such as genetic algorithm in [11] or particle swarm optimization in [12]. Alternative methods take advantage of the convexity of the inner problem (i.e. the system operation) and integrate it in the outer loop using its equivalent KKT conditions [13]. The approach considered here lies on a 'All in One' method where both operating and sizing parameters are variables of a single optimization problem. The objective is to minimize the annualized Total Cost of Ownership (TCO). That cost is calculated with the contribution of the capital expenditures (CAPEX) computed with the cost of the assets and considering the system lifetime $\left(N_{y}=20\right.$ years $) . C^{g e R}(\$ / \mathrm{kW})$ 
is cost of co-generation unit (i.e. gas engine and absorption chiller) that depends on the engine rated power, $C^{p v R}$ is the cost for the installed solar generation, $E^{\text {batR }}$ and $E^{\text {thR }}$ are the cost of electrical and thermal storages in S/kWh and $\$ / \mathrm{RTh}$ respectively. The operating cost $(O P E X)$ is estimated as the system energy bill, with the charge for purchasing electricity and gas as well as the penalty for the peak power imported from the main grid. The OPEX is computed over a representative week with electrical/thermal load profiles at a resolution of $\Delta t=30 \mathrm{~min}$. That $O P E X$ is then multiplied by the number of weeks within a year $\left(N_{w}=52.18\right)$ to finally estimate the TCO over a year ((2)). A full list of used symbols is given in Section I.

$$
\begin{aligned}
& \text { CAPEX }=C^{g e R} \times P^{g e R}+C^{p v R} \times P^{p v R}+C^{b a t R} \times E^{b a t R}+C^{t s R} \times E^{t s R} \\
& \text { OPEX }=\sum_{t \in T}\left(P_{t}^{g d} \times \pi_{t}^{e}+M_{t}^{g e} \times \pi_{t}^{g}\right) \times \Delta t+P^{g d P} \times \pi^{p} \\
& \text { obj: } \min T C O=C A P E X / N_{y}+O P E X \times N_{w}
\end{aligned}
$$

Equations (3) and (4) define the bounds/constraints for the operating and the sizing variables respectively. For the battery and gas engine, the operations are limited by the rated capacities. Note that, contrary to the battery, the design of the thermal storage dissociates power and energy with two different variables $E^{t s R}$ and $P^{t s R}$. The solar power generated is computed by multiplying the value of the installed capacity $P^{g e R}$ by a normalized representative weekly profile $P_{t}^{p v N}$. Also note that an overhead is specified to limit the power imported from the main grid at $50 \%$ more than the base electrical load (for electrical devices except the chiller plant). That value allows the problem feasibility with the chiller plant supplied by the grid in case there is no battery or gas engine.

$$
\begin{aligned}
& \left(0 \leq P_{t}^{g e} \leq P^{g e R} ; 0 \leq\left(P_{t}^{\text {bat }+}, P_{t}^{b a t-}\right) \leq E^{\text {batR }} / 1 \mathrm{~h}\right. \\
& \underline{S O C_{t}^{b a t}} \leq S O C_{t}^{b a t} \leq \overline{S O C^{b a t}} ; 0 \leq P_{t}^{c h}, Q_{t}^{c h-} \\
& 0 \leq\left(Q_{t}^{t s+}, Q_{t}^{t s-}\right) \leq Q^{t s R} ; \quad \underline{S O C_{t}^{t s}} \leq S O C_{t}^{t s} \leq \overline{\operatorname{SOC}^{t s}} \\
& 0 \leq P_{t}^{g d} \leq \max \left(P_{t}^{l}\right)+50 \% ; P_{t}^{g d} \leq P^{g d P} ; P_{t}^{p v}=P_{t}^{p v N} \times P^{p v R} \\
& \int 0 \mathrm{~kW} \leq P^{g e R} \leq 1000 \mathrm{~kW} ; 0 \mathrm{~kW} \leq P^{p v R} \leq 500 \mathrm{kWp} \\
& \left\{0 \mathrm{~kW} \leq E^{\text {batR }} \leq 1000 \mathrm{kWh} ; 0 \mathrm{~kW} \leq E^{t s R} \leq 1000 \mathrm{RTh}\right. \\
& 0 \mathrm{~kW} \leq P^{t s R} \leq \min \left(E^{t s R} / 1 \mathrm{~h}, 100 \mathrm{RT}\right)
\end{aligned}
$$

Equation (5) reflects the typical constraints for energy storage operation with the state of charge (SOC) limit and energy conservation over the time horizon, whereby the final value at the end of the simulated period is equal to the value at the start. However, compared to typical formulation, each side of the constraint is multiplied by the battery capacity in order to avoid non-linearity (the capacity is also a variable of the considered 'all in one' problem). Note that a similar set of constraints has to be considered for the thermal storage. Equation (6) computes the cooling generation for both the chiller and absorption chiller based on their coefficient of performances and the conversion ratio between $\mathrm{RT}$ and $\mathrm{kW}$. The cooling power generation from the absorption chiller is also associated to the electrical consumption of the pumps computed with a fixed coefficient $\left(\beta_{p c r}^{a b c h}\right)$.
TABLE I. PARAMTER RANGE FOR SENSITIVITY ANALYSIS

\begin{tabular}{|ll|ll|}
\hline Param. & Range & Param. & Range \\
\hline$\pi_{t}^{g}$ & $0.5-0.9 \$ / \mathrm{kg}$ & $C^{\text {batR }}$ & $800-2000 \$ / \mathrm{kWh}$ \\
\hline$\pi_{t}^{e}$ & $0.85 \times \pi_{t}^{e}-1.145 \pi_{t}^{e}$ & $C^{t s}$ & $100-200 \$ / \mathrm{RTh}$ \\
\hline$\pi_{t}^{p}$ & $40-60 \$ / \mathrm{kW}$ & $\eta^{\text {bat }}$ & $0.88-0.98$ \\
\hline$C^{g e R}$ & $800-1600 \$ / \mathrm{kW}$ & $\eta^{t s}$ & $0.85-0.95$ \\
\hline$C^{p v R}$ & $750-1750 \$ / \mathrm{kWp}$ & $C O P^{a b c h}$ & $1.05-1.15$ \\
\hline
\end{tabular}

$\underline{S O C^{b a t}} \times E^{b a t R} \leq S O C_{0}^{b a t} \times E^{b a t R}-\sum_{i=1}^{t}\left(\frac{P_{t}^{b a t-}}{\eta^{b a t}}-\eta^{b a t} \times P_{t}^{b a t+}\right) \times 100 \times \Delta t$

$S O C_{0}^{\text {bat }} \times E^{\text {batR }}-\sum_{i=1}^{t}\left(\frac{P_{t}^{\text {bat- }}}{\eta^{\text {bat }}}-\eta^{\text {bat }} \times P_{t}^{\text {bat }}\right) \times 100 \times \Delta t \leq \overline{S O C^{b a t}} \times E^{\text {batR }}$

$S O C_{0}^{\text {bat }} \times E^{\text {batR }}-\sum_{t=1}^{T}\left(\frac{P_{t}^{\text {bat- }}}{\eta^{\text {bat }}}-\eta^{\text {bat }} \times P_{t}^{\text {bat }}\right) \times 100 \times \Delta t \geq S O C_{0}^{\text {bat }} \times E^{\text {batR }}$

$Q_{t}^{c h}=P_{t}^{c h} \times C O P^{c h} / 3.517$

$Q_{t}^{a b c h}=\frac{C O P^{a b c h} \times \beta_{p w h}^{a b c h} \times P_{t}^{g e}}{3.517}$ and $P_{t}^{a b c h}=\beta_{p c r}^{a b c h} \times 3.517 \times Q_{t}^{a b c h}$

Finally, similar to every energy dispatch problem, equation (7) ensures the balance between supply and demand for both thermal and electrical energy vectors.

$$
\begin{aligned}
& P_{t}^{g d+}+P_{t}^{p v}+P_{t}^{g e}+P_{t}^{b a t-}=P_{t}^{l}+P_{t}^{c h}+P_{t}^{a b c h}+P_{t}^{\text {bat }+} \\
& Q_{t}^{c h}+Q_{t}^{a b c h}+Q_{t}^{t s-}=Q_{t}^{l}+Q_{t}^{t s+}
\end{aligned}
$$

\section{Preliminary Sentsitivity Analysis}

The planning problem previously defined is formulated in MATLAB using YALMIP and solved with CPLEX 12.8.1 (16 threads in parallel, $32 \mathrm{~GB}$ RAM, $2.7 \mathrm{~Hz}$ processor). The implemented models are then used to perform a simple sensitivity analysis in order to estimate the TCO variations with different input parameters. The sizes of the equipment remain constant with values at the middle of the range specified in (4). The impacts of energy prices, the cost of the different assets and their efficiencies are then studied using a method similar to a Taylor development around the average point for every parameter (in the range specified in Table I). The electricity prices are based on weekly data for real time prices in Singapore and vary between 85 and $145 \%$ of the original values in the course of the sensitivity analysis. The price for the gas is considered constant under the entire simulated period. Figure 3 displays the results obtained when varying the specified parameters from their middle point (i.e. 0.5 on the $\mathrm{x}$-axis). Gas and electricity prices are the criteria that have the most significant impact on the TCO computed (Figure $3 a$ ) as also observed in [3]. This is to be expected since the OPEX represents around $90 \%$ of the estimated TCO in the investigated scenarios with $10 \%$ corresponding to the annualized CAPEX. That ratio is reflected when comparing Figure $3 a \& 3 b$ with the effect of the equipment cost ten times smaller than the impact of energy prices (magnitude of $1 \%$ compared to magnitude of $10 \%$ ). The contribution of the equipment efficiencies in the TCO variations is even smaller with values around $0.1 \%$ in Figure $3 c$. 

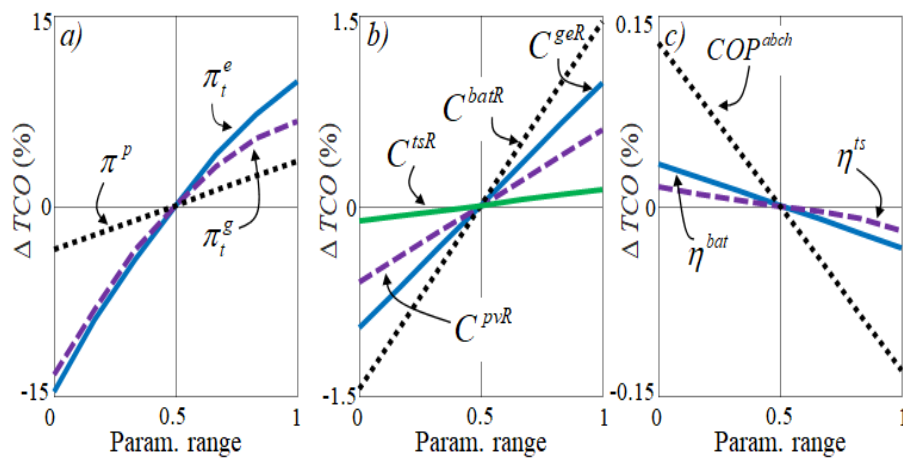

Figure 3. Sensitivity Analysis-a) Energy prices - b) Cost of equipment - c) Efficiencies

\section{SCNENARIO-BASED STOCHASTIC OPTIMIZATION}

As observed in the previous section, the economic environment (i.e. rates, policies/regulation) is an important input parameter for the cost-driven design of multi-energy systems. Thus, the main motivation of the work presented in the paper is to investigate different approaches to incorporate the various economic parameters, rather than implementing high accuracy models for the different equipments. Note that conventional robust optimization for microgrid operation and planning focuses on capturing the uncertainties for the load and/or renewable generation profiles. In this paper, that class of uncertainties is implicitly embedded in the whole representative week considered for the planning problem (which may not be long enough if other geographical areas or types or loads are considered).

\section{A. Stochastic Energy Prices- $\boldsymbol{O P T}_{\boldsymbol{1}}$}

A classical approach is firstly considered to tackle the prices uncertainties and corresponds to scenario-based stochastic optimization. Different values (or levels) are considered for the energy rates $\left(\pi_{t}^{e}, \pi_{t}^{g}\right.$ and $\left.\pi^{p}\right)$ with different probabilities (Figure $4 a$ ). Tests with two, three and five levels are performed (normalized range as in section III.C), and the set of potential scenarios $S$ contains all the possible combinations of prices in every cases. Obviously the total number of scenarios increases significantly when more levels are explored for each parameter (Figure $4 b$ ), which may lead to prohibitive computational times. Each scenario has a probability of occurrence $\lambda_{s}$ computed as the product of the probabilities for each price parameter. The planning problem objective function is then reformulated following (8) with the $O P E X$ computed along all the potential scenarios and weighted by their probabilities. Finally, all the operating variables are defined along the set of potential scenarios $S$ (e.g. $P_{t, s}^{g e}$ ) and the $C A P E X$ calculation remains unchanged as it is not affected by the energy rates.

OPEX $=\sum_{s \in S} \lambda_{s} \times\left(\sum_{t \in T}\left(P_{t, s}^{g d} \times \pi_{t, s}^{e}+M_{t, s}^{g e} \times \pi_{t, s}^{g}\right) \times \Delta t+P_{s}^{g d P} \times \pi_{s}^{p}\right)$

\section{B. Multi-Period Optimization-OPT2}

When the system design is expected to have an operational lifetime in the range of decades (tpypically 20-30 years), it is not realistic to adopt constant values for the different energy rates. Thus, another way to model the economic environment consist in discretizing the planning period into sub-periods $p$ representing a set $P$. Similar to the previous problem formulation, the $O P E X$ computation is affected ((9)) and the operating variables are defined along the set $P$. For each period $p$, the $O P E X$ is then divided by the number of years in the sub-period so that the final TCO remains on a yearly basis. Note that the price for peak power is projected to be constant over the planning period in the optimization and that the gas and electricity rates are projected to increase by $28 \%$ and $15 \%$ respectively (www.eia.gov).

OPEX $=\sum_{p \in P} \sum_{t \in T} \frac{\left(P_{t, p}^{g d} \times \pi_{t, p}^{e}+M_{t, p}^{g e} \times \pi_{t, p}^{g}\right) \times \Delta t+P_{p}^{g d P} \times \pi^{p}}{N_{y} / \# P}$

\section{Multi-Period Stochastic Optimization - $\boldsymbol{O P T}_{3}$}

Another possible method to model the economic environment could consist in combining OPT 1 and $\mathbf{O P T}_{2}$. Thus, different set of price profiles are considered along the periods $p$ and with different probabilities of occurrence (Figure 5), similar to the scenario-based approach implemented in [6]. In the considered test case, four periods of five years each are considered in the planning over 20 years. The $O P E X$ computation is re-formulated $((10))$ and the operating variables are defined over the sets $T, P$ and $S$, which tends to significantly increase the problem complexity if too many potential scenarios are investigated (i.e. high number of different levels for the parameters).

OPEX $=\sum_{s \in S} \lambda_{s} \times \sum_{p \in P} \sum_{t \in T} \frac{\left(P_{t, p, s}^{g d} \times \pi_{t, p, s}^{e}+M_{t, p, s}^{g e} \times \pi_{t, p, s}^{g}\right) \times \Delta t+P_{p, s}^{g d P} \times \pi_{s}^{p}}{N_{y} / \# P}$
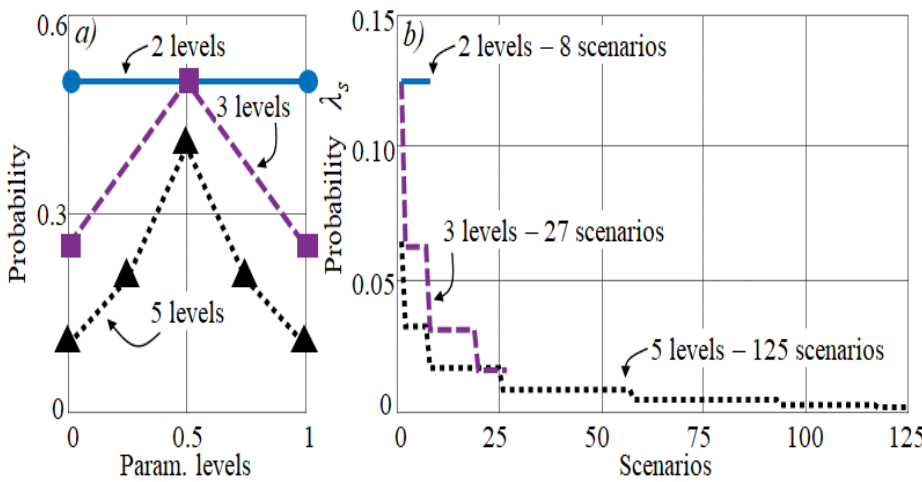

Figure 4. Stochastic prices-a) Price levels - b) Set of scenatios
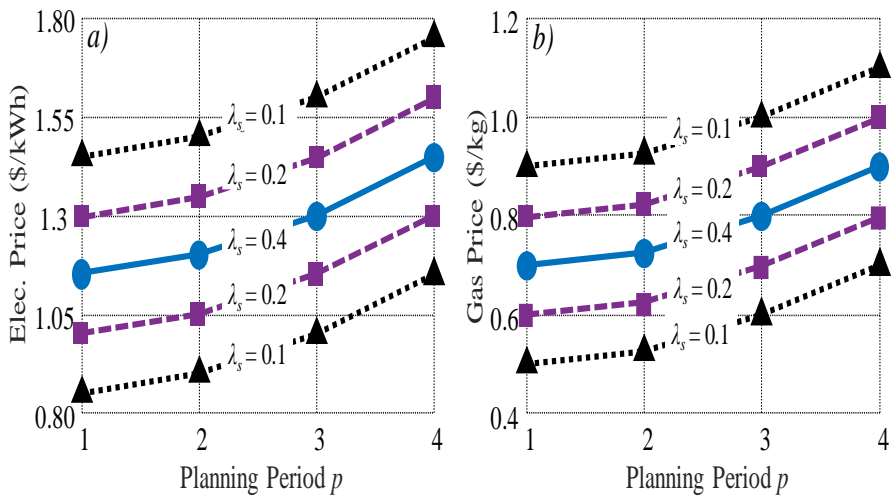

Figure 5. Stochastic prices over years (5 levels)-a) Electricity - b) Gas 
TABle II. OBTAINED RESUlts FOR DIFFERENT PROBLEM FoRMULATIONS

\begin{tabular}{|c|c|c|c|c|c|c|c|c|c|c|}
\hline & $\mathrm{OPT}_{0}$ & $\begin{array}{c}\text { OPT }_{1} \\
2 \text { levels }\end{array}$ & $\begin{array}{c}\mathrm{OPT}_{1} \\
3 \text { levels }\end{array}$ & $\begin{array}{c}\mathrm{OPT}_{1} \\
5 \text { levels }\end{array}$ & $\mathrm{OPT}_{2}$ & $\begin{array}{c}\mathrm{OPT}_{3} \\
2 \text { levels }\end{array}$ & $\begin{array}{c}\mathrm{OPT}_{3} \\
3 \text { levels }\end{array}$ & $\begin{array}{c}\mathrm{OPT}_{3} \\
5 \text { levels }\end{array}$ & $\begin{array}{c}\mathrm{OPT}_{4} \\
2 \text { levels }\end{array}$ & $\begin{array}{c}\mathrm{OPT}_{4} \\
3 \text { levels }\end{array}$ \\
\hline \multicolumn{11}{|l|}{ Results } \\
\hline$P^{g e R}(\mathrm{~kW})$ & 348 & 929 & 786 & 739 & 301 & 801 & 735 & 393 & 929 & - \\
\hline$P^{p v R}(\mathrm{~kW})$ & 500 & 500 & 500 & 500 & 500 & 500 & 500 & 500 & 500 & - \\
\hline$E^{\text {batR }}(\mathrm{kWh})$ & 149 & 149 & 121 & 119 & 149 & 136 & 119 & 119 & 149 & - \\
\hline$E^{t s R}(\mathrm{RTh})$ & 283 & 283 & 115 & 100 & 283 & 206 & 100 & 100 & 283 & - \\
\hline$P^{t s R}(\mathrm{RT})$ & 100 & 100 & 100 & 100 & 100 & 100 & 100 & 100 & 100 & - \\
\hline$C A P E X(\mathrm{k} \$)$ & 64 & 99 & 87 & 84 & 50 & 90 & 84 & 64 & 99 & - \\
\hline$O P E X(\mathrm{k} \$)$ & 996 & 896 & 939 & 957 & 967 & 1,010 & 1,045 & 1,078 & 896 & - \\
\hline$T C O(\mathrm{k} \$)$ & 1,060 & 995 & 1,026 & 1,041 & 1,017 & 1,100 & 1,130 & 1,142 & 995 & - \\
\hline \multicolumn{11}{|l|}{ Computation } \\
\hline Nb. Variables & 3,702 & 27,229 & 91,088 & 420,466 & 13,785 & 107,893 & 369,329 & $1,680,841$ & 430,549 & $7,350,848$ \\
\hline $\mathrm{Nb}$. Constraints & 8,413 & 64,875 & 218,129 & $1,008,597$ & 32,616 & 258,459 & 871,475 & $4,033,347$ & $1,032,795$ & $17,640,689$ \\
\hline CPU Time & $4 \mathrm{~s}$ & $13 \mathrm{~s}$ & $1 \mathrm{~min}$ & $20 \mathrm{~min}$ & $5 \mathrm{~s}$ & $1 \mathrm{~min}$ & $15 \mathrm{~min}$ & $3 \mathrm{~h}$ & $3 \mathrm{~min}$ & - \\
\hline
\end{tabular}

\section{Stochastic Energy Prices and Equipment Costs - OPT 4}

Another investigated problem formulation that captures the economic uncertainties consists in considering stochastic values for the equipment cost as well as for the energy prices. Similar to OPT 1 and $\mathbf{O P T}_{\mathbf{3}}$, a set of different likely scenarios $s$ is defined depending on the values of electricity/gas/peak rates ( 3 parameters) and the price level for the different types of assets (4 parameters). For a given size of the assets, the $C A P E X$ is calculated according to (11) with the equipment cost taking different values and with the corresponding scenario probability $\lambda_{s}$. The $O P E X$ calculation is the same as in (8). Note that, compared to $\mathbf{O P T}_{\mathbf{1}}$, the problem formulated here includes a larger number of scenarios for the same number of price levels as there are more parameters involved in the uncertainties consideration.

$$
C A P E X=\sum_{s \in S} \lambda_{s} \times\left(C_{s}^{g e R} \times P^{g e R}+C_{s}^{p v R} \times P^{p v R}+C_{s}^{\text {batR }} \times E^{\text {batR }}+C_{s}^{t s R} \times E^{t s R}\right)
$$

\section{E. Obtained Results}

Several optimizations are run following the different formulations described in the previous subsections. The results are displayed in Table II with OPT $_{0}$ denoting the base case problem presented in Section III. As every formulation is different, the obtained values in terms of TCO are obviously different in every cases and vary from $978 \mathrm{k} \$$ to $1,110 \mathrm{k} \$$. As highlighted by the sensitivity analysis, those variations are mainly explained by different representations of the economic context. It is important to note that all the cases are mathematically different and do not correspond to a same problem. The different formulations then do not have to be compared in terms of TCO but rather with regard to the obtained value for the size of the different assets. Those different simulations have to be interpreted a different ways to tackle the planning issues. In terms of optimal sizes of the equipment, the PV is systematically set at the maximum allowed capacity (upper bound at $500 \mathrm{~kW}$ ) as it represents immediate energy/cost savings with low investment costs compared to the other assets. The size of the battery displays small variations around $130 \mathrm{kWh}$ on average depending on the cases while the results for the thermal storage varies more significantly from 100 to $283 \mathrm{RTh}$. The most noticeable outcome is the gas engine optimal capacities covering $60 \%$ $(301-929 \mathrm{~kW})$ of the specified range $0-1 \mathrm{MW}$ depending on the problem formulations. This specifically shows the necessity to pay the most attention to the modeling of the economic environment, which is likely to be more uncertain than load or solar radiation profiles, especially when planning decades ahead.
However, a stochastic representation that allows to fully capture the uncertainties over the planning period may result in higher complexity with intractable problems due to the increased number of variables and constraints - especially if too many scenarios are investigated - see $\mathbf{O P T}_{\mathbf{3}}$ and 3 levels for energy prices and equipment cost. The obtained results show a great variety of solutions with small variations of the objective function (i.e. the yearly $T C O$ here). That outcome is explained by the nature of the planning problem with the objective function in terms of yearly TCO and a small contribution of the equipment cost compared to the operating expenditures. Figure 6 displays small variations of the TCO around the optimal solution. The gas engine and energy storages capacities can vary significantly ( $>50 \%$ of the specified range) without varying the $T C O$ by more than $5 \%$. This implies that under the specified equipment cost and energy prices, the capital expenditures are somewhat compensated by the OPEX savings. Ultimately, that 'flatness' of such long term planning problem with linear formulation implicitly guarantees the robustness of the results.

\section{CONCLUSIONS}

While optimal design of multi-energy systems under uncertainties has been widely addressed in literature, this paper aims at a step back in order to estimate the relevance of complex problem formulation. After a sensitivity analysis is performed, it is showed that the energy prices are, by far, the most impacting parameter, which is consistent with the conclusions drawn in [3]. This paper investigates different formulations in order to model the economic environment with different energy rates as well as uncertain equipment costs.

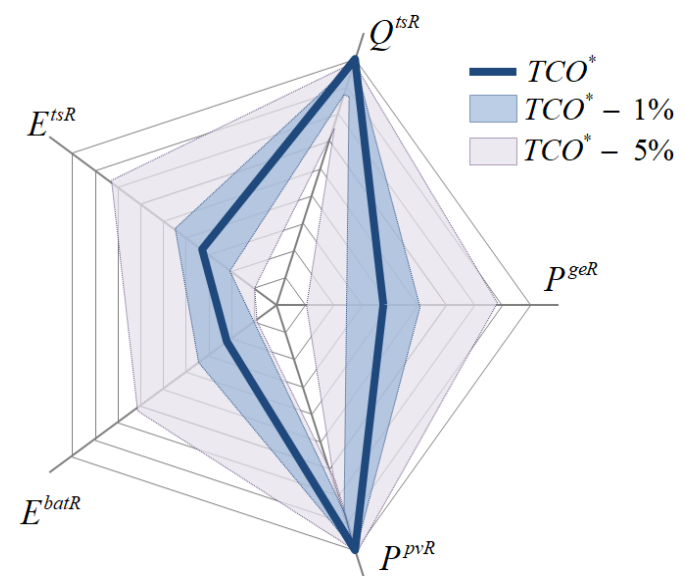

Figure 6. Small variations of TCO around the best solution 
Ten different optimization runs are performed with various assumptions and choices of models. The problem complexity tends to increase drastically when high numbers of stochastic scenarios are explored, which leads non tractability, even with the simple linear models considered here. The obtained results display significant differences in terms of installed capacities while the objective remain somewhat constant due to the chosen hypothesis to represent the price uncertainties (close to a normal law, centered on the average value compared to uniform law for instance). That outcome is also explained by the nature of the planning problem itself with wide 'flat' areas in the search space regarding the objective function. Thus, in addition to the robustness with respect to the input parameters (e.g. the prices here), such planning problem should also be tackled in terms of robustness of the results. Those results should then be expressed as intervals/sub-search space and not only vectors, and the search for a unique global optimum with the all the sources of uncertainties may not be the most suitable approach. The idea would be to include new constraints in the optimization in order to return the widest 'clusters' with small variations around the cluster optimal value of the objective. Those should be part of further developments that would require customized problem formulations and/or solving methods.

\section{REFERENCES}

[1] K. Jana, A. Ray, M. Mansouri Majoumerd, M. Assadi, S. De, "Polygeneration as a future sustainable energy solution - A comprehensive review", Appl. Energy, vol 202, pp. 88-111, Sep. 2017.

[2] C. Gamarra, J.M. Guerrero. "Computational optimization techniques applied to microgrids planning: A review", Renew. Sust. Energ. Rev., vol 48, pp. 413-424, 2015.

[3] G. Mavromatidisa, K. Orehounig, J. Carmeliet, "Uncertainty and global sensitivity analysis for the optimal design of distributed energy systems", Appl. Energy, vol. 214, pp 219-238, 2018.

[4] F.S. Gazijahani, J. Salehi "Robust design of microgrids with reconfigurable topology under severe uncertainty", IEEE. Trans. Sustain. Energy, vol 9, no. 2, pp. 559-569, Apr. 2018.

[5] M. Zachar, P. Daoutidis, "Microgrid/macrogrid energy exchange: a novel market structure and stochastic scheduling", IEEE Trans. Smart Grid, vol 8, no. 1, pp. 178-189, Jan. 2017.

[6] H. Alharbi, K. Bhattacharya, "Stochastic optimal planning of battery energy storage system for isolated microgrids", IEEE. Trans. Sustain. Energy, vol 9, no. 1, pp. 211-255, Jan. 2018.

[7] A. Narayan, K. Ponnambalam, "Risk-averse stochastic programming approach for microgrid planning under uncertainties", Renew. Energy, vol 101, pp. 399-408, 2017.

[8] R. Rigo-Mariani, S. O. Chea Wae, S. Mazzoni, and A. Romagnoli, "Comparison of optimization frameworks for the design of a multienergy microgrid," Applied Energy, vol. 257, Jan. 2020.

[9] S. Pfenninger, "Dealing with multiple decades of hourly wind and PV time series in energy models: A comparison of methods to reduce time resolution and the planning implications of inter-annual variability", Applied Energy, vol 197, 2017.

[10] S. Mazzoni, G. Cerri, L. Chennaoui, "A Simulation tool for concentrated solar power based on micro gas turbine engine", Energ. Convers. Manage., vol 174, pp. 844-854, 2018.

[11] B. Li, R. Roche, A. Miraoui, "Microgrid sizing with combined evolutionary algorithm and MILP unit commitment", Appl. Energy, vol 188, pp. 547-562, 2017.

[12] M. H. Moradi, M. Eskandari, H. Showkati, "A hybrid method for simultaneous optimization of DG capacity and operational strategy in microgrids utilizing renewable energy resources", Int. J. Elec. Power, vol 56, pp. 241-258, 2014.

[13] M. Quashie, G. Joos, "Optimal Planning of Urban Microgrids with an Energy Management System", IEEE Power Engineering Society Transmission and Distribution Conf., Dallas, USA, 2016. 